\title{
Image Gently: Partnerships to promote radiation protection for children worldwide
}

\author{
Marilyn J. Goske • Kimberly E. Applegate • \\ Priscilla S. Butler • Donald P. Frush • \\ Gregory Morrison • Keith J. Strauss • \\ on behalf of the Alliance for Radiation Safety \\ in Pediatric Imaging
}

(C) Springer-Verlag 2011

\begin{abstract}
Strategies to promote radiation protection for children worldwide can be challenging to implement at a local level. On the other hand, partnerships among established agencies, scientific societies and other groups can have a far greater impact at the local level, effecting change more rapidly and broadly compared to each group acting alone. Through collaboration, there is less redundancy of effort and these groups can promote the unique strength of each organization. This paper reviews the different groups that have worked with the Image Gently campaign and discusses international approaches to achieve their desired outcome of radiation protection for children throughout the world.
\end{abstract}

Disclaimer Authors have no financial interests, investigational or offlabel uses to disclose.

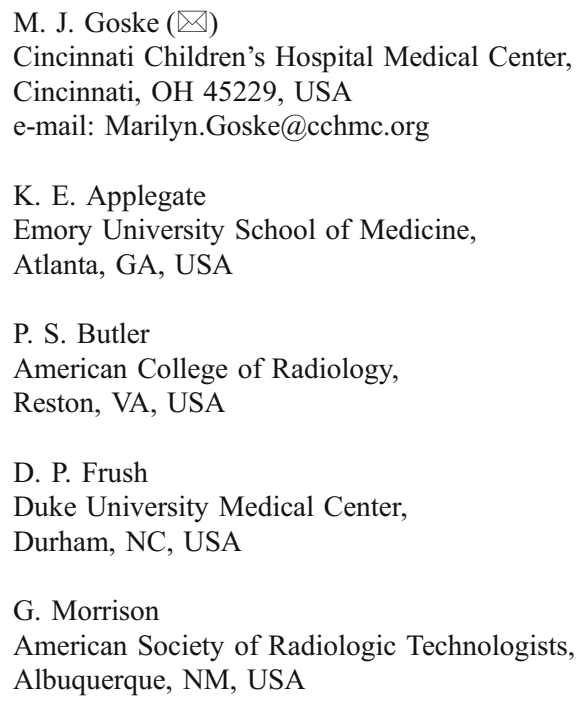

K. J. Strauss Children's Hospital Boston, Boston, MA, USA
Image Gently is a social marketing campaign that was started in 2007 by the Society for Pediatric Radiology, the American Society of Radiologic Technologists, the American College of Radiology and the American Association of Physicists in Medicine to raise awareness, develop education materials and advocate for children in promoting radiation protection. This group founded the Alliance for Radiation Safety in Pediatric Imaging, which now has 62 members, 25 of them international. Fortunately for children worldwide, there are many active international groups, some with immense global reach, that have worked on this initiative for many years. This paper will review how the collaborative efforts among the groups have been instrumental in bringing attention to this issue, emphasizing the unique perspective of each organization as complementary strategies for outreach efforts to different audiences around the world. Some of the information below is taken from each organization's website and these sources are gratefully acknowledged. The following is an incomplete list of the organizations that have contributed to this international effort.

The International Atomic Energy Agency (IAEA) (www.iaea.org) is a large worldwide organization centered in Vienna, Austria, that describes itself as "the world's center of cooperation in the nuclear field." Under the United Nations authority, it was created in 1957 as the "Atoms for Peace" organization in follow-up to World War II. According to its website, the agency works with its member nations and multiple partners worldwide to promote safe, secure and peaceful use of all facets of nuclear technology. Specifically, the Alliance for Radiation Safety in Pediatric Imaging has worked with the Radiation Protection of Patients unit. This group is responsible for developing and directing multi-national projects on medical radiation protection, education and training and quality assurance activities in more than 60 countries. Steering committee members of the 
Alliance have acted as consultants for several of these international and multi-national projects, particularly in developing countries; have exchanged website educational links (see www.rpop.iaea.org) and have recently edited material for physicists in pediatric radiology in the form of 10 CD modules. In the past, Donald Frush, MD, has been an international leader representing pediatric radiology as a participant in the Smart Card/SmartRadTrack Project, Keith Strauss, medical imaging physicist, is currently serving on an IAEA task group developing a manual on pediatric radiation. Through shared goals, the Alliance and IAEA actively work on specific survey projects and documents that impact pediatric patient care under the leadership of Dr. Madan Rehani, this year's honorary member of the Society for Pediatric Radiology at the IPR meeting in London in May 2011.

The International Radiation Protection Association (IRPA) (www.irpa.net) arose from initiatives of the Health Physics Society (USA) in the early 1960s. This group was one of the first in the medical imaging profession to determine the need for an international umbrella organization of national health physics societies. The primary purpose of IRPA is to provide a forum where those engaged in radiation protection activities in all countries can communicate more readily and through this process advance radiation protection in many parts of the world. This includes "relevant aspects of such branches of knowledge as science, medicine, engineering, technology and law, to provide for the protection of man and his environment from the hazards caused by radiation, and thereby to facilitate the safe use of medical, scientific, and industrial radiological practices for the benefit of mankind." This society has been instrumental in fostering radiation protection through large regional and international meetings where scientific papers and workshops highlight and promote progress in radiation biology, radiation safety, and radiation protection. Image Gently is working with IRPA to partner with these societies in the development of guiding principles of radiation protection for radiation workers - be they in medicine, nuclear power, research or industry.

The International Radiology Quality Network (IRQN) (www.irqn.org) is a relative newcomer, formed in 2002 by Dr. Lawrence Lau, a radiologist in Australia. The network's objective is to promote quality in radiology through collaboration, experience sharing and mutual assistance with the motto "Collaboration is strength." The IRQN is interested in matters related to the elements that are fundamental to the delivery of quality radiology services, the promotion of evidence-based and appropriate utilization of radiology, the processes relating to quality control, quality assurance, quality improvement and practice accreditation. The members of the network meet at least annually and communicate by email regularly between face-to-face meetings. In collaboration with the World Health Organization, Image Gently and other international organizations, they are leading a new initiative to develop simple, universal guidelines for medical imaging that will reduce radiation exposure to patients.

The International Society of Radiology (ISR) (www. isradiology.org) is an umbrella organization of national radiology societies, with the goal of advancing radiology education globally. The first International Congress of Radiology was held in 1925. At the seventh congress, in 1953, the formal structure of the International Society of Radiology was created. Since then, the ISR has continued to sponsor international congresses and has expanded its activities to offer free educational online lectures ("virtual congress") from the meeting to members around the world. A few years ago, the ISR's website was created and contains open source radiology textbooks for use around the world. More recently, through agreements with major radiology journals, the group created the "Go Rad: Global Outreach Radiology" advanced radiology education site for the global radiology community by aggregating current, practical radiology literature with content targeted and dedicated to developing nations and underserved populations. Most major radiology journals publish online and offer educational content of tremendous value to radiologists and other related healthcare providers, but free and easy access to newly published content is only available to subscribers.

Through activism, this group was able to obtain agreements with major radiology journals to provide immediate, open access to a limited amount of otherwise restricted-access content, providing an electronic link back to the original on-line article, at the time of first publication. The immediate past-president, Dr. Hans Ringertz, a leading Swedish pediatric radiologist, has promoted links to the Image Gently web site and created educational posters and materials targeted to reduce radiation dose for medical imaging in pediatric patients.

The International Society of Radiographers and Radiological Technologists (ISRRT) (www.isrrt.org) was created in 1962 by 15 national societies and by 2006 had grown to 80 member societies. The objectives are to assist the education of radiographers and to support the development of medical radiation technology worldwide. Analogous to the ISR, membership is open to any national society that includes radiographers or radiological technologists within its membership. The objectives of ISRRT are to advance the science and practice of radiography and allied subjects by the promotion of improved standards of education and of research in the technical aspects of radiation medicine and radiation protection, to make the results of research and experience in radiation medicine and radiation protection available to practitioners throughout the world while furthering the objects of the society. Its partnership with Image Gently in the dissemination of educational materials for radiographers and radiological technologists throughout the world and the translations of 
Image Gently materials into various languages is critical to the advancement of radiation protection initiatives.

The World Health Organization (WHO) (http://www. who.int/ionizing_radiation/about/med_exposure/en/index1. $\mathrm{html}$ ) was formed when diplomats met to form the United Nations in 1945. These talks led to the creation of this wellrecognized global health organization, now known as the WHO. The WHO's constitution, under the United Nations, came into force on 7 April 1948 - a date celebrated every year as World Health Day. The WHO fulfills its objectives through its core functions of "providing leadership on matters critical to health and engaging in partnerships where joint action is needed; shaping the research agenda and stimulating the generation, translation and dissemination of valuable knowledge; setting norms and standards and promoting and monitoring their implementation; articulating ethical and evidence-based policy options; providing technical support, catalyzing change, and building sustainable institutional capacity; and monitoring the health situation and assessing health trends." WHO is conducting a Global Initiative on Radiation Safety in Health Care Settings. Dr. Maria Perez works with Image Gently as well as with health authorities, professional societies, and international organizations, to promote safe and effective use of radiation in health care. One project, in collaboration with the IRQN, is focused on the development of consensus guidelines for imaging that will reduce unjustified radiation exposure to patients. The Alliance participated in the kick-off meeting of this project (March 2010). Another project is collaboration with Image Gently, the Environmental Protection Agency and other partners to create educational brochures for consumers about the risks and benefits of CT scanning.

Under its Global Initiative on Radiation Safety in Health Care Settings, the WHO has hosted two international conferences at which the Alliance has participated, including the International Conference of Children's Health and the Environment in June, 2009, and more recently a workshop titled "Communicating Radiation Risks in Pediatric Imaging" in September, 2010. The Alliance contributed to the special session titled "Appropriate use of radiation in pediatric imaging: challenges and opportunities" (May 2010) and the seminar titled "Towards safer and effective use of radiation in pediatric healthcare" (June 2010), organized by
WHO during regional IRPA Congresses held in Europe and Asia. One goal of these events was to increase awareness of radiation as a potential public health issue for children. (http://www.who.int/ionizing radiation/about/med exposure/ en/index 1.html)

The Brazilian College of Radiology and Diagnostic Imaging (Colégio Brasileiro de Radiologia e Diagnóstico por Imagem-CBR/Sociedad Latino Americana de Radiología Pediátrica-SLARP (The Latin American Society of Pediatric Radiologists) (www.cbr.org.br). The Brazilian College of Radiology has been a leader in South America by adopting the Image Gently campaign and promoting its tenets of "child-sizing" the radiation dose throughout the country and at its large national Congresses. Arising from the leadership of Dr. Ines Boechet and her close working relationships with Drs. Henrique Lederman, Sebastião Cezar Mendes Tramontin, Pedro Dalto, Dolores Bustelo and Norma Selma Costas, the CBR elected to translate the Image Gently CT campaign materials for use throughout Brazil. Promoting its message and highlighting the need for attention to radiation protection for children, the CBR used readily available materials on the Image Gently website to create a unique campaign of its own in Brazil. Chili has followed suit with a similar campaign and support of the tenets of the Image Gently campaign.

Sixteen international translations Finally, under the leadership of Dr. Kimberly Applegate, who has spearheaded the outreach efforts of the Alliance, the Image Gently website has 16 foreign language translations, through the efforts of more than 50 international volunteer translators. Each of the translations of the $\mathrm{CT}$ and interventional parent brochures was vetted by at least three medical professionals and is available free for download and use around the world. The Alliance is working toward the translation of all of the educational brochures.

In conclusion, this report briefly highlights the critical work of many radiology and medical physics groups that have demonstrated leadership in radiation protection worldwide. As we continue to work together, the strengths of each help to reach a broad audience with the goal of enhancing safety for children undergoing medical imaging. 